\title{
Hydrogeological and geotechnical rock property characterization from geophysics
}

\section{N. R. Brerton, C. J. Evans and A. Kingdon}

British Geological Survey, Keyworth, Nottingham NG12 5GG, UK (e-mail:r.brereton@bgs.ac.uk)

\section{SUMMARY}

Boreholes drilled at Sellafield penetrated a variety of rock units. Core samples and wireline logs indicate that rock mass properties and in situ fluid properties vary from one unit to another, but that properties are relatively uniform for each unit within a particular borehole. Variability is superimposed upon the bulk rock mass properties, however, where faults or zones of fractured rock intersect a borehole. Furthermore, lateral variability within a particular unit may be expected between boreholes and throughout the rock volume.

The primary objectives of the work were: to establish a means of determining the spatial heterogeneity and distribution of rock mass and fluid properties using measurements made on core samples and derived from wireline logs; to determine the spatial heterogeneity and distribution of rock mass properties away from boreholes and in three-dimensions, by extrapolating the detailed understanding gained from boreholes into the seismic survey volume; and to develop a visualization model of rock mass properties in three-dimensions.

It has been demonstrated that acoustic impedance is the principal property in common between surface seismic and borehole measurements, and that it provides a link between the various scales of measurement. Dynamic rock quality and hydrogeological indices have been developed which allow qualitative comparisons to be made between the boreholes. Empirical relationships have also been established between acoustic impedance and rock quality, and between acoustic impedance and hydrogeological properties. These relationships enable continuous profile quantitative estimations of Rock Mass Rating and hydraulic conductivity to be made from wireline logs, and have allowed these properties to be extrapolated into the seismic acoustic impedance volume, thereby providing three-dimensional visualizations of the spatial heterogeneity of rock mass properties. 